\title{
Relation between ST segment elevation during dobutamine stress test and myocardial viability after a recent myocardial infarction
}

\author{
Abdou Elhendy, Jan H Cornel, Jos R T C Roelandt, Ron T van Domburg, \\ Marcel L Geleijnse, Peter R Nierop, Jeroen J Bax, Antonio Sciarra, M Mohsen Ibrahim, \\ Medhat El-Refaee, Galal M El-Said, Paolo M Fioretti
}

\begin{abstract}
Objective-To assess the relation between ST segment elevation during the dobutamine stress test and late improvement of function after acute $Q$ wave myocardial infarction.
\end{abstract}

Patients and design-70 patients were studied a mean (SD) 8 (3) days after acute myocardial infarction with high dose dobutamine-atropine stress echocardiography and a follow up echocardiogram at 85 (10) days. A score model based on 16 segments and four grades was used to assess left ventricular function. Functional improvement was defined as a reduction of wall motion score $\geqslant 1$ in $\geqslant 1$ segments at follow up.

Intervention-Myocardial revascularisation was performed in 23 patients (33\%) before follow up studies.

Results-ST segment elevation occurred in 40 patients $(57 \%)$. Late functional improvement occurred in 35 patients (50\%). Functional improvement was more common in patients with ST segment elevation $(68 \% v 30 \%, P<0.005)$ and they had a higher mean (SD) number of improved segments at follow up (1.9 (2.2) $v$ $0.5(1 \cdot 1), P<0 \cdot 005)$. The wall motion score index decreased between baseline and follow up in patients with ST segment elevation $(1.54(0.50) v 1.48(0.43), P<$ $0.05)$ but not in patients without ST segment elevation $(1.39(0.60) v 1.45(0.47))$. The accuracy of ST segment elevation for the prediction of functional improvement was similar to that of low dose dobutamine echocardiography in patients with anterior infarction (80\% v 83\%) and in patients who underwent revascularisation ( $78 \% v 83 \%$ respectively).

Conclusion-In patients with a recent $Q$ wave myocardial infarction, dobutamineinduced ST segment elevation is a valuable marker of myocardial viability particularly when the test is performed without or with suboptimal echocardiographic imaging.

(Heart 1997;77:115-121)

Keywords: dobutamine stress test; ST segment elevation; myocardial viability
The detection of myocardial viability after myocardial infarction is important for the proper selection of patients in whom myocardial function is more likely to improve after revascularisation. ${ }^{1-4}$ Thallium scintigraphy, positron emission tomography, and low dose dobutamine (LDD) echocardiography are useful methods for detecting myocardial viability. ${ }^{1-6}$ Stress-induced ST segment elevation has been reported as a specific marker of residual viability. ${ }^{78}$ However, the relation between this pattern and functional improvement of dyssynergic myocardium, occurring spontaneously or after revascularisation, has not been studied. The dobutamine stress test (DST) is a method of simulating exercise that is increasingly used for the functional assessment of patients after myocardial infarction. ${ }^{9-13}$ We have previously reported that normalisation of negative $T$ waves in the electrocardiogram during LDD infusion in patients with a recent myocardial infarction is a marker of myocardial viability and a predictor of late improvement of function. ${ }^{14}$ ST segment elevation is a common finding in such patients during DST. ${ }^{15} 16$ The aims of this study were to find the relation between ST elevation during DST after a recent myocardial infarction and myocardial viability assessed by LDD echocardiography and to compare the value of ST segment elevation and LDD echocardiography in the prediction of late improvement of left ventricular function.

\section{Patients and methods}

PATIENT SELECTION

The study comprised 70 patients with a recent myocardial infarction who were enrolled in a research protocol to assess the value of dobutamine stress echocardiography in the functional evaluation of patients after acute myocardial infarction. All patients fulfilled the following criteria: (a) a recent myocardial infarction ( $\leqslant 2$ weeks before) diagnosed by the standard criteria of chest pain, cardiac enzymes, and electrocardiographic changes; $(b)$ the absence of severe heart failure, hypotension, high grade ventricular arrhythmias, or chest pain not responding to medical treatment; (c) the presence of pathological $Q$ waves and wall motion abnormalities in the corresponding segments at the day of the study; $(d)$ absence of myocardial aneurysm, left ventricular hypertrophy, or bundle branch block. All patients gave an 
informed consent to participate in the study. There were 49 men $(70 \%)$. The mean (SD) age was 58 (11) years. Thirty one patients (44\%) were receiving oral nitrates and/or calcium channel blockers. Twenty one patients $(30 \%)$ were receiving angiotensin converting enzyme (ACE) inhibitors. Treatment with $\beta$ blockers was stopped one day before the test.

\section{DOBUTAMINE STRESS TEST}

DST was performed a mean (SD) of 8 (3) days after infarction (range 6-14 days). Dobutamine was infused through an antecubital vein starting at a dose of $5 \mu \mathrm{g} / \mathrm{kg} / \mathrm{min}$ for three minutes, 10 $\mu \mathrm{g} / \mathrm{kg} / \mathrm{min}$ for three minutes, increasing by $10 \mu \mathrm{g} / \mathrm{kg} / \mathrm{min}$ every three minutes to a maximum of $40 \mu \mathrm{g} / \mathrm{kg} / \mathrm{min}$. Atropine (up to $1 \mathrm{mg}$ ) was given to patients who did not achieve $85 \%$ of their age predicted maximal heart rate. ${ }^{17} \mathrm{~A}$ three lead electrocardiogram was continuously monitored and a 12 lead electrocardiogram was recorded each minute. The level of the ST segment was calculated by a computer-assisted system (Cardiovet CSG/12, Schiller) after signal averaging. Blood pressure was measured every three minutes. The electrocardiograms were reviewed by two cardiologists unaware of the echocardiographic data. ST segment elevation was defined as new or additional $\geqslant 0 \cdot 1$ $\mathrm{mV}$ elevation of the $\mathrm{J}$ point with a horizontal or upsloping ST segment lasting $80 \mathrm{~ms}$ during stress in $\geqslant 2 Q$ leads, with the $P Q$ segment regarded as the isoelectric line. ${ }^{18} \mathrm{ST}$ segment depression was defined as $\geqslant 0.1 \mathrm{mV}$ horizontal or downsloping depression $80 \mathrm{~ms}$ after the $\mathrm{J}$ point, below baseline level. The test was interrupted if severe chest pain, ST segment depression $>2 \mathrm{~mm}$, significant arrhythmia, or a fall in systolic blood pressure $>40 \mathrm{~mm} \mathrm{Hg}$ occurred during the test.

\section{STRESS ECHOCARDIOGRAPHY}

The echocardiogram was performed using the standard views and was recorded on video tape at rest and during stress. Rest, $L D D$, and peak stress images were also digitised and stored on an optical disk (Vingmed CFM 800) for a display in quad-screen format. A 16-segment model was used to assess left ventricular function. ${ }^{19}$ Each segment was graded with a fourpoint score grading ( $1=$ normal or hyperkinesis; 2 = hypokinesis; 3 = akinesis; $4=$ dyskinesis). Wall motion score index was derived by the summation of the score of the 16 segments divided by 16 . The test was regarded as positive for the viability if $\geqslant 1$ dyssynergic segment had a decrease of $\geqslant 1$ in wall motion score during $\operatorname{LDD}(5-10 \mu \mathrm{g} / \mathrm{kg} / \mathrm{min})$. The viability index was defined as the number of dyssynergic segments showing improvement at LDD divided by the total number of dyssynergic segments. The diagnosis of ischaemia was based on the occurrence of new or worsening wall motion abnormalities. Ischaemia was not deemed to be present when akinetic segments at rest became dyskinetic without improvement at LDD. ${ }^{20}{ }^{21}$ Images were assessed by two experienced investigators without knowledge of the patients' electrocardiographic data. When they disagreed, a majority decision was achieved by a third investigator. In our centre, inter and intra observer agreement on the interpretation of dobutamine stress echocardiographic studies are $91 \%$ and $92 \%$ respectively. ${ }^{22}$

\section{FOLLOW UP STUDIES}

A rest echocardiogram was performed in all patients 85 (10) days after infarction (range 71-98 days). Regional improvement of function was defined as a decrease of wall motion score $\geqslant 1$ grade in $\geqslant 1$ segments. The improvement index was derived by dividing the number of improved segments at follow up by the total number of dyssynergic segments in the initial study.

\section{CORONARY ANGIOGRAPHY}

Coronary angiography was performed using the Judkins technique, within a month after infarction in 34 patients (49\%). Significant coronary artery disease was defined as a diameter stenosis $\geqslant 50 \%$ in one or more major epicardial arteries.

\section{ASSIGNMENT OF THE ELECTROCARDIOGRAM TO} MYOCARDIAL SEGMENTS

Two electrocardiographic segments were identified: (a) the anterior segment which included leads V1-V4 and was assigned to the anterior wall, the interventricular septum, and the apical anterior and apical septal segments, and to the left anterior descending coronary artery at angiography; (b) the inferolateral segment which included leads II, III, aVF, I, aVL, V5, and V6 and was assigned to the inferior and posterolateral wall and to the left circumflex and the right coronary artery at angiography. The apical lateral and apical inferior segments were considered as overlap segments between the anterior and inferolateral locations and were assigned to the region with concomitant abnormalities. Regional wall motion score index was derived by dividing the regional wall motion score by the number of segments in that region. Regional viability and improvement indices were derived in a similar way.

\section{STATISTICAL ANALYSIS}

Unless specified, data are presented as mean (SD) values. The chi square test was used to compare differences between proportions. Student's $t$ test was used for analysis of continuous data. A P value $<0.05$ was considered statistically significant. Sensitivity, specificity, and accuracy were derived according to the standard definition and were presented with the corresponding $95 \%$ confidence intervals (CI).

\section{Results}

DOBUTAMINE STRESS TEST

There was a significant increase of heart rate, systolic blood pressure, and rate-pressure product from rest to peak stress (71 (13) $v 136$ (18) beats/minute $(\mathrm{P}<0.001), 121$ (27) $v 137$ (30) $\mathrm{mm} \mathrm{Hg}(\mathrm{P}<0.01)$, and 8631 (1543) $v 18619$ (4325) $(P<0.0001)$ respectively). The ratepressure product did not change significantly from rest to LDD. The test was terminated before reaching the maximal dose or the target 
Table 1 Clinical features and haemodynamic data in patients with recent $Q$ wave myocardial infarction with (group $A$ ) and without (group B) ST segment elevation

\begin{tabular}{lcc}
\hline & Group $A(n=40)$ & Group B $(n=30)$ \\
\hline Age (years) & $57(11)$ & $61(11)$ \\
Male gender & $31(78 \%)$ & $18(60 \%)$ \\
Anterior infarction & $18(45 \%)$ & $12(40 \%)$ \\
Inferior infarction & $26(65 \%) \dagger$ & $18(60 \%)$ \\
Thrombolysis & $21(53 \%)$ & $13(43 \%)$ \\
Peak HR & $141(18)$ & $130(18)^{\star}$ \\
Peak SBP & $134(25)$ & $142(36)$ \\
Peak rate-pressure product & $775(3806)$ & $1838(5129)$ \\
85\% of target HR achieved & $32(80 \%)$ & $22(73 \%)$ \\
Maximal dobutamine dose & $39(4)$ & $37(8)$ \\
Angina during the test & $7(18 \%)$ & $7(27 \%)$ \\
ST segment depression & $22(55 \%)$ & $7(23 \%)$ \\
\hline
\end{tabular}

SBP, systolic blood pressure ( $\mathrm{mm} \mathrm{Hg}$ ); $\mathrm{HR}$, heart rate (beats/min); WMA, wall motion abnormalities. ${ }^{\star} P<0 \cdot 01$. +4 patients had $S T$ segment elevation in anterior leads as well.

Table 2 Echocardiographic data from dobutamine stress test and follow up in patients with $Q$ wave myocardial infarction with (group $A$ ) and without (group $B$ ) ST segment elevation

\begin{tabular}{lcc}
\hline & Group $A(n=40)$ & Group $B(n=30)$ \\
\hline Dyssynergic segments (n) & $5 \cdot 9(3 \cdot 8)$ & $4 \cdot 7(3.9)$ \\
Resting WMSI & $1 \cdot 54(0 \cdot 05)$ & $1 \cdot 39(0 \cdot 06)$ \\
LDD WMSI & $1 \cdot 12(0 \cdot 03)$ & $1 \cdot 15(0 \cdot 43)$ \\
Follow up WMSI & $1 \cdot 48(0 \cdot 43)$ & $1.45(0 \cdot 47)$ \\
Viability at LDD (cases) & $27(68 \%)$ & $12(40 \%)^{\star}$ \\
Viable segments at LDD & $1 \cdot 8(2 \cdot 2)$ & $1 \cdot 1(1 \cdot 6)$ \\
LDD viability index & $0 \cdot 34(0 \cdot 36)$ & $0 \cdot 33(0 \cdot 42)$ \\
Improvement at follow up (cases) & $26(68 \%)$ & $9(30 \%) \dagger$ \\
Improved segments (n) & $1.9(2 \cdot 2)$ & $0 \cdot 5(1 \cdot 1) \dagger$ \\
Improvement index & $0 \cdot 38(0 \cdot 36)$ & $0 \cdot 22(0 \cdot 40)$ \\
Ischaemia at high dose (cases) & $20(50 \%)$ & $12(40 \%)$ \\
\hline
\end{tabular}

LDD, low dose dobutamine echocardiography; WMSI, wall motion score index; ${ }^{\star} \mathrm{P}<0.05$ $+\mathrm{P}<0.005$.

heart rate because of angina in seven patients, ST segment depression in one patient, and hypotension in one patient. One patient had atrial fibrillation at peak dobutamine dose. $\mathrm{He}$ was successfully treated by pharmacological cardioversion. Two patients had a short ventricular tachycardia ( $<10$ complexes). Fifty four patients $(77 \%)$ achieved $85 \%$ of the maximal heart rate predicted for age. Atropine was administered in 22 patients (31\%). Angina occurred in 15 patients (21\%) and ST segment depression in 29 patients (41\%). ST segment elevation was present in 24 patients (34\%) at rest. New or additional ST segment elevation in $Q$ leads occurred in 40 patients $(57 \%)$ during stress (group $\mathrm{A}$ ). The remaining 30 patients (43\%) made up group B and included five patients with ST segment elevation at rest who had no further elevation during stress. The mean heart rate at ST segment elevation was 109 (24) beats/min $(P<0.01 v$ resting heart rate). The mean dobutamine dose at ST segment elevation was 31 (11) $\mu \mathrm{g} / \mathrm{kg} / \mathrm{min}$.

Table 3 Regional echocardiographic data of dobutamine stress test and follow up in patients with recent anterior $Q$ wave myocardial infarction with (group $A$ ) and without (group B) ST segment elevation

\begin{tabular}{lcc}
\hline & Group $A(n=18)$ & Group $B(n=12)$ \\
\hline Dyssynergic segments (n) & $6 \cdot 3(2 \cdot 4)$ & $4 \cdot 7(3 \cdot 1)$ \\
Resting WMSI & $1 \cdot 99(0 \cdot 43)$ & $1 \cdot 86(0 \cdot 66)$ \\
LDD WMSI & $1 \cdot 79(0 \cdot 48)$ & $1 \cdot 84(0 \cdot 68)$ \\
Follow up WMSI & $1 \cdot 79(0 \cdot 59)$ & $1 \cdot 90(0 \cdot 73)$ \\
Viability at LDD (cases) & $14(78 \%)$ & $3(25 \%)^{\star}$ \\
Viable segments at LDD & $1 \cdot 7(2 \cdot 2)$ & $0 \cdot 2(0 \cdot 4) \dagger$ \\
LDD viability index & $28 \cdot 8(34 \cdot 8)$ & $12 \cdot 2(33 \cdot 1)$ \\
Improvement at follow up (cases) & $15(83 \%)$ & $3(25 \%)^{\star}$ \\
Improved segments (n) & $2 \cdot 2(2 \cdot 2)$ & $0 \cdot 1(0 \cdot 3) \dagger$ \\
Improvement index & $0 \cdot 40(0 \cdot 37)$ & $0 \cdot 11(0 \cdot 33) \ddagger$ \\
Peri-infarction ischaemia (cases) & $5(28 \%)$ & $4(25 \%)$
\end{tabular}

LDD, low dose dobutamine echocardiography; WMSI, wall motion score index; ${ }^{\mathrm{P}}<0.005$, $\dagger \mathrm{P}<0.0001, \neq \mathrm{P}<0.05$.
STRESS ECHOCARDIOGRAPHY

All patients had wall motion abnormalities at rest. Among 377 dyssynergic segments in regions corresponding to $Q$ waves, $106 \mathrm{seg}$ ments (28\%) improved at LDD. The wall motion score index decreased significantly from rest to $\operatorname{LDD}(1.49(0.33) v 1.39(0.36)$, $\mathbf{P}<0.0001)$. Ischaemia was detected in 32 patients (46\%). At follow up function had improved in 95 (25\%) of the 377 dyssynergic segments in 35 patients (50\%).

\section{COMPARISON OF PATIENTS WITH (GROUP A)}

AND WITHOUT (GROUP B) ST SEGMENT ELEVATION

Clinical and haemodynamic data (table 1)

There were no significant differences between group A and B with respect to thrombolytic therapy, angina during stress, peak rate-pressure product, and percentage of patients achieving $85 \%$ of the target heart rate. Patients of group A had a higher peak heart rate and more of them had ST segment depression.

Echocardiographic data (table 2)

There was a trend to a higher resting wall motion score index and a higher number of dyssynergic segments in group A. There was no significant difference between both groups with respect to prevalence of ischaemia. Group A patients had a higher prevalence of viability pattern at $\mathrm{LDD}$, a higher prevalence of regional improvement and a higher number of improved segments at follow up. The wall motion score index decreased between baseline and follow up in group $A(P<0.05)$ but not in group $B$. In group $A$ there were no significant differences between patients with and without late functional improvement with respect to heart rate at $S T$ segment elevation (108 (25) $v 112$ (22) beats/min) or dobutamine dose at ST segment elevation (31 (11) $\mu \mathrm{g} / \mathrm{kg} / \mathrm{min}$ in both).

Patients who were receiving ACE inhibitors had a higher resting wall motion score index $(1.76(0.44) v 1.38(0.31), \mathrm{P}<0.0001)$, a higher frequency of anterior myocardial infarction $(62 \% v 37 \%, P=0.05)$, a somewhat higher frequency of ST segment elevation $(38 \% v 20 \%, \mathrm{P}=0 \cdot 1)$, and a similar frequency of late functional improvement $(43 \% v$ $53 \%, P=N S$ ) compared with patients who were not receiving ACE inhibitors.

ANTERIOR VERSUS INFERIOR MYOCARDIAL INFARCTION

In patients with anterior infarction (table 3 ) there was a trend to a higher regional wall motion score index and a higher number of dyssynergic segments at rest in group $\mathrm{A}$. The frequency of a viability pattern and the number of viable segments at LDD was higher in group A. At follow up the frequency of functional improvement, number of improved segments (fig 1), and improvement index were higher in group A. The regional wall motion score index decreased between baseline and follow up studies (fig 2$)$ in group $A(P<0.05)$ and showed a slight non-significant increase in group $B$. In patients with inferior infarction 
Figure 1 Number of dyssynergic segments improvement in patients with recent $Q$ wave myocardial infarction (MI) with and without $S T$ segment elevation during dobutamine stress test. showing late functional

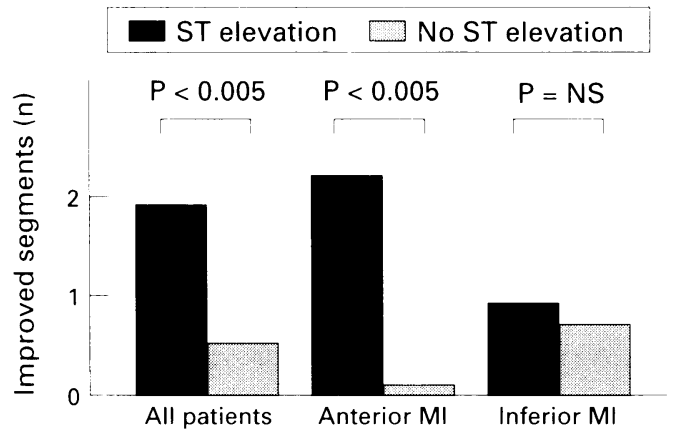

Figure 2 Regional wall motion score index (WMSI) at baseline, low dose dobutamine testing, and follow up echocardiogram in patients with recent anterior $Q$ wave myocardial infarction with and without ST segment elevation during dobutamine stress test.

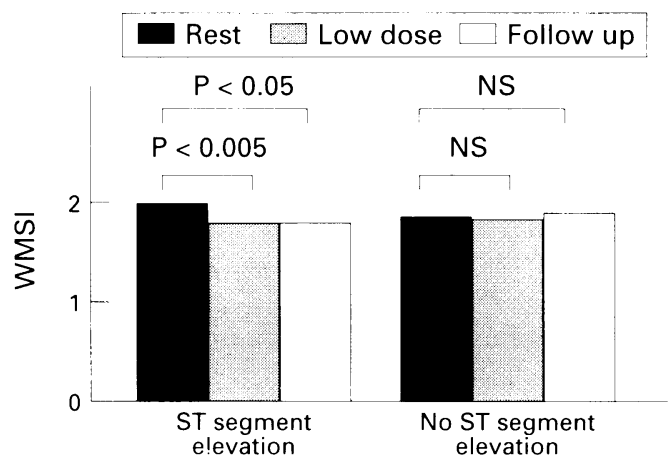

(table 4, including four patients who also had ST segment elevation in the anterior leads) these variables were similar in both groups. There was a slight, non-significant decrease in wall motion score index (fig 3 ) from rest to follow up in group A and a slight non-significant increase in group B. The frequency of overall, peri-infarction, or remote ischaemia was not significantly different between group A and B regardless of the site of infarction. The sensitivity, specificity, and accuracy of ST segment elevation and LDD echocardiography for the prediction of functional improvements in different groups are shown in table 5. The accuracy of ST segment elevation was higher in patients with anterior infarction than in those with inferior infarction $(80 \%$ v $57 \%, \mathrm{P}<$ $0.05)$. In patients with anterior infarction the accuracy of LDD echocardiography was similar to that of ST segment elevation $(83 \% v$ $80 \%)$ whereas in patients with inferior infarction the accuracy of LDD echocardiography was higher than that of ST segment elevation $(77 \% v 57 \%, \mathrm{P}<0.05)$. The mean number of segments that had recovered was somewhat higher in patients with anterior than inferior myocardial infarction $(1.4(2 \cdot 2)$ v $0.8(1.3), \mathrm{P}$ $=0.08)$. Figure 4 shows the distribution of

Table 4 Regional echocardiographic data of dobutamine stress test and follow up in patients with inferior $Q$ wave myocardial infarction with (group $A$ ) and without (group $B$ ) ST segment elevation

\begin{tabular}{lcc}
\hline & Group $A(n=18)$ & Group $B(n=12)$ \\
\hline Dyssynergic segments (n) & $2 \cdot 5(1 \cdot 6)$ & $2 \cdot 7(1 \cdot 5)$ \\
Resting WMSI & $1 \cdot 57(0 \cdot 37)$ & $1 \cdot 51(0 \cdot 27)$ \\
LDD WMSI & $1 \cdot 42(0 \cdot 04)$ & $1 \cdot 32(0 \cdot 35)$ \\
Follow up WMSI & $1 \cdot 50(0 \cdot 43)$ & $1 \cdot 55(0 \cdot 47)$ \\
Viability at LDD (cases) & $15(58 \%)$ & $10(56 \%)$ \\
Viable segments at LDD & $1 \cdot 0(1 \cdot 1)$ & $1 \cdot 0(1 \cdot 3)$ \\
LDD viability index & $38 \cdot 1(39 \cdot 2)$ & $48 \cdot 2(49 \cdot 1)$ \\
Improvement at follow up (cases) & $13(50 \%)$ & $6(33 \%)$ \\
Improved segments (n) & $0 \cdot 9(1 \cdot 2)$ & $0 \cdot 7(1 \cdot 1)$ \\
Improvement index & $0 \cdot 32(0 \cdot 39)$ & $0 \cdot 31(0 \cdot 46)$ \\
Peri-infarction ischaemia (cases) & $10(38 \%)$ & $5(28 \%)$ \\
\hline
\end{tabular}

LDD, low dose dobutamine echocardiography; WMSI, wall motion score index.

functional recovery in various combinations of ST segment elevation and viability pattern at LDD echocardiography in patients with anterior myocardial infarction. Late improvement of function occurred in 12 of the 14 patients with both ST segment elevation and a viability pattern at LDD echocardiography, (positive predictive value $=86 \%$ ), whereas no improvement occurred in any of the nine patients with neither ST segment elevation nor viability at LDD echocardiography (negative predictive value $=100 \%$ )

\section{CORONARY ANGIOGRAPHY AND}

REVASCULARISATION PROCEDURES.

Coronary angiography was performed in 19 patients in group A and in 15 in group B. Coronary angioplasty of the infarct related artery was successfully performed before DST in 11 patients (six patients in group $\mathrm{A}$ and five patient in group B). There was no significant difference between both groups with respect to frequency of multivessel disease $(42 \% v 33 \%)$ or significant stenosis of the infarct related artery $(68 \% v 67 \%)$. Twelve patients underwent a revascularisation procedure 15 (8) days after DST. In these patients the interval between intervention and follow up ranged from 35 to 83 days (mean 72 days). Intervention included coronary angioplasty (three patients in group A and three patients of group B) and coronary artery bypass grafting (four patients in group A and of two in group B). In the 34 patients in whom coronary angiography was performed, functional improvement occurred in 12 of 23 patients $(52 \%)$ with and in five of 11 patients $(45 \%)$ without revascularisation $(P=N S)$. In patients who underwent revascularisation the accuracy of ST segment elevation for the prediction of late functional improvement was comparable to that of LDD echocardiography (78\% v 83\% respectively; table 5).

The decision to perform coronary angiography and subsequent revascularisation was taken by the individual cardiologist. Chest pain was the leading cause of referral. The decision was not based on the results of DST, except in one patient who had $4 \mathrm{~mm}$ ST segment depression in five leads. Coronary angiography showed three vessel disease and the patient was referred for coronary artery bypass grafting.

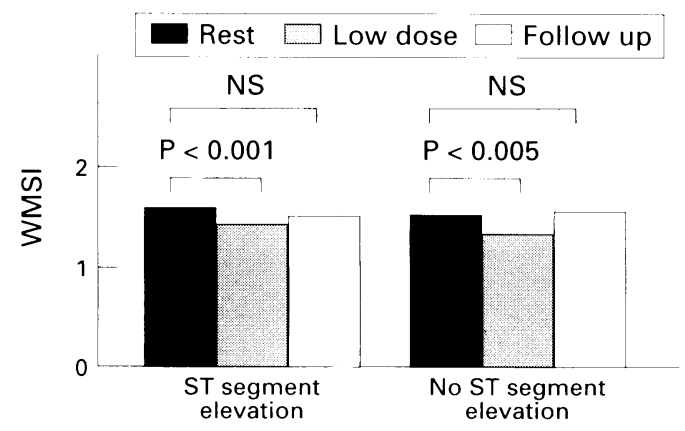

Figure 3 Regional wall motion score index (WMSI) at baseline, low dose dobutamine, and follow up echocardiogram in patients with recent inferior $Q$ wave myocardial infarction with and without $S T$ segment elevation during dobutamine stress test. 
Table 5 Diagnostic accuracy (\%) with 95\% confidence intervals of low dose dobutamine echocardiography and ST segment elevation during dobutamine stress test for the prediction of overall and regional late improvement of left ventricular function after a recent myocardial infarction. Results presented as \% (95\% CI)

\begin{tabular}{llllll}
\hline & SENS & SPEC & $P P V$ & NPV & ACC \\
\hline LDDE overall & $83(74-92)$ & $71(61-82)$ & $74(64-85)$ & $81(71-90)$ & $77(67-87)$ \\
LDDE anterior & $83(70-97)$ & $83(70-97)$ & $88(77-100)$ & $77(62-92)$ & $83(70-97)$ \\
LDDE inferior & $89(80-99)$ & $68(54-82)$ & $68(54-82)$ & $89(80-99)$ & $77(65-90)$ \\
STE overall & $74(64-85)$ & $60(49-71)$ & $65(54-76)$ & $70(59-81)$ & $67(56-78)$ \\
STE anterior & $83(70-97)$ & $75(60-90)$ & $83(70-97)$ & $75(60-90)$ & $80(66-94)$ \\
STE inferior & $68(55-82)$ & $48(33-63)$ & $50(35-65)$ & $67(53-81)$ & $57(42-71)$ \\
LDDE (revasc) & $83(68-99)$ & $82(66-98)$ & $83(68-99)$ & $82(66-98)$ & $83(67-98)$ \\
STE (revasc) & $83(68-99)$ & $73(54-91)$ & $77(60-94)$ & $80(64-96)$ & $78(61-95)$ \\
\hline
\end{tabular}

ACC, diagnostic accuracy; CI, confidence intervals; LDDE, low dose dobutamine echocardiography; NPV, negative predictive value; PPV, positive predictive value; SENS, sensitivity; SPEC, specificity; STE, ST segment elevation; revasc, revascularised patients ( $n=23$ patients).

\section{Discussion}

This is the first study to evaluate the relation between stress-induced ST segment elevation and improvement of function after myocardial infarction. The results of our study show that in patients evaluated 8 days after a recent $Q$ wave myocardial infarction, dobutamine-induced ST segment elevation was associated with a higher frequency and extent of functional improvement of the dyssynergic myocardium 2-3 months after infarction compared with patients without ST segment elevation. Global left ventricular function, as assessed by wall motion score index improved at follow up in patients with dobutamine-induced ST segment elevation but not in those without. The difference was more evident in anterior than inferior infarction. The accuracy of ST segment elevation for the prediction of functional improvement was comparable to that of LDD echocardiography in patients with anterior infarction and in those who underwent revascularisation. This higher frequency of functional recovery in patients with ST segment elevation occurred despite their more severe baseline wall motion abnormalities. Revascularisation was performed in only $33 \%$ of patients and it is possible that myocardial stunning was more severe and functional improvement took more time in patients with more extensive wall motion abnormalities who developed ST segment elevation. Therefore patients with ST segment elevation had a higher rate of late functional improvement than patients without ST segment elevation in whom myocardial stunning is presumed to be less severe and might have been completely or partially resolved before DST. The exact mechanism underlying the relation between ST segment elevation and myocardial viability is not clear. In patients with viable

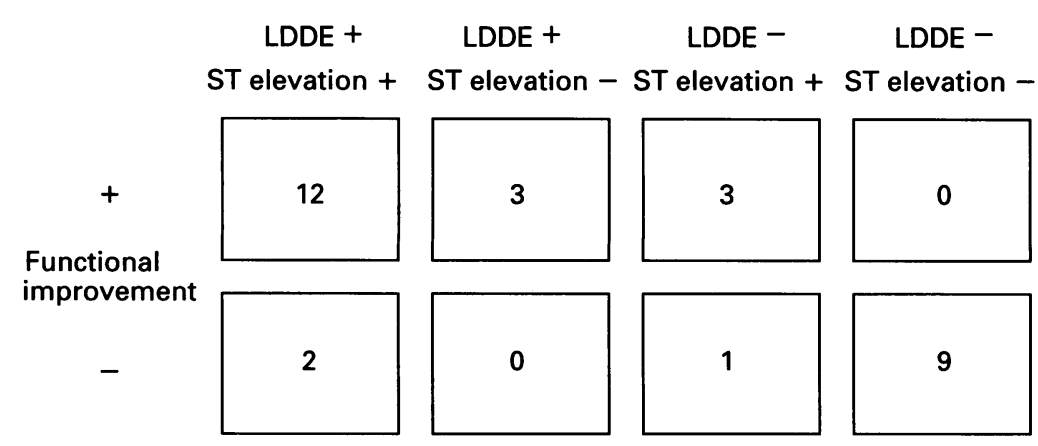

Figure 4 Distribution of late functional recovery in patients with anterior myocardial infarction in various combinations of ST segment elevation and viability pattern during low-dose dobutamine echocardiography (LDDE). myocardium it is possible that sympathetic stimulation during exercise or DST produces heterogeneous contraction in the infarct zone because there are viable segments that improve and non-viable segments that move paradoxically or do not improve. This heterogeneity of contraction may be the underlying mechanism of ST segment elevation in patients with viable myocardium. There are several explanations for the similar frequency of functional improvement in patients with and without revascularisation: (a) a predominant role of myocardial stunning rather than hibernation particularly in the group without revascularisation; $(b)$ in patients who underwent coronary artery bypass grafting myocardial stunning after the cardiopulmonary bypass might have needed longer to resolve; (c) a follow up coronary angiogram was not performed to document sustained benefit of the revascularisation; (d) some revascularisation procedures had been performed before DST.

\section{STRESS-INDUCED ST SEGMENT ELEVATION} AFTER MYOCARDIAL INFARCTION

Exercise-induced ST segment elevation was more common in patients with recent than with old myocardial infarction. ${ }^{7}$ The difference may be explained by a high frequency of myocardial viability in patients with recent infarction. This viable myocardium may improve (spontaneously or after revascularisation), ${ }^{23}$ undergo necrosis, or continue as ischaemic hibernating myocardium. In the first two situations, viable myocardium will no longer exist and ST segment elevation will become less common as the infarct gets older. It has been shown that most recently infarcted myocardial regions retain residual metabolic activity, the extent of which is inversely related to the time since the acute event. Exercise-induced ST segment elevation was more common in patients with than without FDG uptake in the underperfused regions. ${ }^{24}$

\section{RELATION BETWEEN ST SEGMENT ELEVATION} AND MYOCARDIAL ISCHAEMIA

We found no significant difference in the proportions of patients with ischaemia in those with or without ST segment elevation during DST: this is consistent with our previous study using MIBI SPECT imaging. ${ }^{25}$ The higher prevalence of ST segment depression in patients with ST segment elevation can be explained by the occurrence of reciprocal changes without true ischaemia. ${ }^{15}$ Similar find- 
ings have been reported by Coma-Canella et $a l^{16}$ and by other authors using exercise testing. ${ }^{26-28}$ In contrast, Shimonagata et $a l^{29}$ and Margonato et $a l^{30}$ reported that exerciseinduced ST segment elevation after a recent myocardial infarction is specific for ischaemia on thallium scintigraphy.

\section{STRESS-INDUCED ST SEGMENT ELEVATION AS A} MARKER OF VIABILITY

Margonato et al reported that exercise-induced ST segment elevation in patients with previous myocardial infarction is highly specific for viability assessed by positron emission tomography. ${ }^{7}$ The accuracy of ST segment elevation was higher in anterior infarction than inferior infarction. This may be explained by the need for an adequate mass of viable myocardium for the occurrence of ST segment elevation, which is more available in anterior infarction than inferior infarction. The relatively higher mean number of segments with functional recovery in patients with anterior infarction than those with inferior myocardial infarction in our study supports this contention. The similar accuracy of LDD echocardiography and ST segment elevation for the prediction of functional recovery in patients who underwent revascularisation in our study may be related to the higher frequency of anterior infarction in the latter group and the low likelihood of the persistence of myocardial hibernation after revascularisation.

Lombardo et al have recently reported that in patients with chronic left ventricular dysfunction, ST segment elevation during DST is a specific marker of myocardial viability as judged by LDD echocardiography only if ST segment elevation developed at LDD. ${ }^{8}$ In our study ST segment elevation was associated with a significant increase of heart rate and occurred mostly at doses $>10 \mu \mathrm{g} / \mathrm{kg} / \mathrm{min}$. This is not surprising, because the heart rate does not increase significantly at LDD. ${ }^{14}$ Previous studies have shown the importance of an increase in heart rate for the occurrence of ST segment elevation during exercise. ${ }^{27}$ In our study the mean heart rate and mean dobutamine dose at ST segment elevation were not different in patients with functional improvement or without. In contrast to these studies, Lanzarini et al found no significant difference in the frequency or extent of the viability pattern at LDD echocardiography with or without dobutamine-induced ST segment elevation in 42 patients studied after acute myocardial infarction. ${ }^{31}$ However, no data regarding the functional recovery were provided. Our study shows that the difference between patients with and without ST segment elevation is more evident by using indices of late functional improvement than indices of viability at LDD echocardiography. This may be explained by some limitations of the latter in identification of viable myocardium. The sensitivity of LDD echocardiography for the detection of stunned myocardium was shown to be relatively low in akinetic segments. ${ }^{5}$ Wall motion of a viable akinetic segment may not be seen during LDD because of tethering by an adjacent necrotic segment. Additionally, the possible occurrence of ischaemia at $\mathrm{LDD}$, as has been recently reported, ${ }^{32}$ may inhibit the contractile response of dyssynergic segments. These contributing mechanisms underscore the importance of the assessment of functional recovery as well as the markers of myocardial viability..$^{33}$

\section{LIMITATIONS OF THE STUDY}

Global left ventricular function was assessed by semiquantitative evaluation of wall motion rather than ejection fraction. However, even ejection fraction has its own limitations as a measure of contractility, being dependent on loading conditions and heart rate. Wall motion score index has been regarded as being analogous to the ejection fraction ${ }^{34}$ and may even provide an advantage over ejection fraction in the serial assessment of left ventricular function after acute myocardial infarction. That is because regional dyssynergy after acute myocardial infarction is associated with compensatory hypertrophy in adjacent segments which tends to maintain ejection fraction. When dyssynergic myocardium improves at follow up, compensatory hypertrophy will resolve and the improvement of regional function may not be associated with an equivalent increase of ejection fraction. ${ }^{35}$

The anatomy of the infarct related artery was not established in all patients. We cannot exclude the possibility that some of the persistently dyssynergic segments may improve after revascularisation. However, there was no rationale to catheterise asymptomatic patients with an uncomplicated clinical course. Our study could not define the underlying mechanism of reversible dysfunction after acute myocardial infarction. However, distinguishing between myocardial stunning and hibernation in these patients is a challenge. Improvement of function after early revascularisation does not rule out myocardial stunning as a mechanism of reversible dysfunction because we have previously shown that about one third of dyssynergic segments detected one week after infarction improve spontaneously after three months..$^{5614}$ On the other hand spontaneous improvement of function may not represent pure myocardial stunning. Spontaneous thrombolysis and the development of collateral channels may improve myocardial perfusion and provide a source of natural revascularisation with subsequent improvement of a hibernating myocardium..$^{36}$ This is supported by our previous finding of spontaneous improvement of thallium uptake by dyssynergic segments which showed functional recovery three months after myocardial infarction. ${ }^{6}$ An alternative explanation of this finding is a spontaneous improvement of cellular mechanisms involved in thallium uptake.

\section{SUMMARY AND CONCLUSIONS}

In patients with recent $Q$ wave myocardial infarction undergoing pre-discharge high dose DST the frequency and extent of late improvement of left ventricular function are greater in patients with ST segment elevation during DST than in those without. The accuracy of ST segment elevation for the predic- 
tion of functional improvement is comparable to that of LDD echocardiography in patients with anterior infarction and in those who undergo myocardial revascularisation. Although some discourage the use of electrocardiographic recording during dobutamine stress echocardiography, ${ }^{37}$ we recommend that more attention should be given to the proper positioning of electrocardiographic leads and obtaining high quality tracings, particularly when the test is performed without or with suboptimal echocardiographic imaging.

This study was supported by the Department of Cardiology, Cairo University Hospital, Cairo, Egypt. We thank Ilonk Hoffmanns van den Ancker for arranging the follow up studies.

1 Ragosta M, Beller GA, Watson DD, Kaul S, Gimple LW. Quantitative planar rest-redistribution 201-Tl imaging in detection of myocardial viability and prediction of improvement in left ventricular function after coronary bypass surgery in patients with severely depressed left bypass surgery in patients with severely depress
ventricular function. Circulation 1993;87:1630-41.

2 Barilla F, Gheorghiade M, Alam M, Khaja F, Goldstein S. Low-dose dobutamine in patients with acute myocardial
infarction identifies viable but not contractile infarction identifies viable but not contractile myocardium and predicts the magnitude of improvement in wall motion abnormalities in response to coro

3 Arnese M, Cornel JH, Salustri A, Maat APWM, Elhendy A, Reijs AEM, et al. Prediction of improvement of regional left ventricular function after surgical revascularization: a comparison of low-dose-dobutamine echocar-
diography with 201-T1 single-photon emission computed tomography. Circulation 1995;91:2748-52.

4 Smart SG, Sawada S, Ryan T, Segar D, Atherton L Berkovitz $\mathrm{K}$, et al. Low-dose dobutamine echocardiography detects reversible dysfunction after thrombolytic therapy of acute myocardial infarction. Circulation 1993;88:405-15.

5 Salustri A, Elhendy A, Garyfallidis P, Ciavatti M, Cornel $\mathrm{JH}$, Ten Cate FJ, et al. Prediction of improvement of venJH, Ten Cate Fo, et al. Prediction of improvement of venusing low-dose dobutamine stress echocardiography. $A m \mathcal{F}$ Cardiol 1994;74:853-6.

6 Elhendy A, Trocino G, Salustri A, Cornel JH, Roelandt JRTC, Boersma E, et al. Low-dose dobutamine echocardiography and rest-redistribution thallium-201 tomography in the assessment of spontaneous recovery of left ventricular function after recent myocardial infarction. Am Heart f 1996;131:1088-96.

7 Margonato A, Chierchia SL, Xuereb RG, Xuereb M Fragasso G, Cappelletti A, et al. Specificity and sensitivity of exercise-induced ST-segment elevation for detection of residual viability: Comparison with fluorodeoxyglucose and positron emission tomography. $7 \mathrm{Am}$ Coll Cardiol 1995;25:1032-8.

8 Lombardo A, Loperfido F, Pennestri F, Rossi E, Patrizi R, Cristinziani G, et al. Significance of transient ST-T changes during dobutamine testing in $Q$ wave myocardial infarction. $\Im$ Am Coll Cardiol 1996;27:599-605.

9 Berthe C, Pierard LA, Hiernaux M, Trotteur G Lempereur P, Carlier J, et al. Predicting the extent and location of coronary artery disease in acute myocardial location of coronary artery disease in acute myocardial infarction by echocardiography during
sion. Am $\mathcal{F}$ Cardiol $1986 ; 58: 1167-72$.

10 Elhendy A, van Domburg RT, Roelandt JRTC, Geleijnse ML, Cornel JH, El-Said GM, et al. Accuracy of dobutamine stress echocardiography for the diagnosis of coronary artery stenosis in patients with myocardial infarction: the impact of extent and severity of left ventricular dysfunction. Heart 1996;76:123-8.

11 Elhendy A, Geleijnse ML, Roelandt JRTC, van Domburg RT, TenCate FI, Nierop PR, et al. Comparison of dobutamine stress echocardiography and $99 \mathrm{M}$-technetium sestamibi SPECT myocardial perfusion scintigraphy in predicting the extent of coronary artery disease in patients with healed myocardial infarction. $A m \mathcal{F}$ Cardiol; in press.

12 Coma-Canella I, Gomes Martinez MV, Rodrigo F, Castro Beiras JM. The dobutamine stress test with thallium-201 single-photon emission computed tomography and radionuclide angiography: postinfarction study. $₹ \mathrm{Am}$ Coll radionuclide angiography:

13 Elhendy A, Cornel JH, Roelandt JRTC, van Domburg RT, Geleijnse ML, Hoeymans PAJ, et al. Dobutamine 201thallium SPECT imaging for the assessment of periinfarction and remote myocardial ischemia. $f$ Nucl Med; in press.

14 Salustri A, Garyfallidis P, Elhendy A, Ciavatti M, Cornel $\mathrm{JH}$, Gemelli $\mathrm{A}$, et al. $\mathrm{T}$-wave normalization during dobutamine echocardiography for the diagnosis of viable myocardium. Am f Cardiol 1995;75:505-7.

15 Coma-Canella I. Significance of ST-segment changes induced by dobutamine stress test after acute myocardial infarction. Which are reciprocal? Eur Heart $\mathcal{f} 1991$; 12:909-16.

16 Coma-Canella I, Gomez MV, Terol I, Rodrigo F, Castro JM. Radionuclide studies in patients with stress-induced ST-segment elevation after acute myocardial infarction Am Heart $\mathcal{F}$ 1994;128:459-65.

17 Mc Neill AJ, Fioretti PM, El-Said EM, Salustri A, Forster T, Roelandt JRTC. Enhanced sensitivity for detection of coronary artery disease by addition of atropine to dobutamine stress echocardiography. Am $\mathcal{f}$ Cardiol 1992;70: 41-6.

18 Dunn RF, Bailey IK, Roger U, Kelly DT. Exercise-induced ST-segment elevation correlation of thallium 201 perfusion scanning and coronary arteriography. Circulation sion scanning and

19 Schiller NB, Shah PM, Crawford M, DeMaria A, Devereux R, Feigenbaum $\mathrm{H}$, et al. Recommendations for quantitation of the left ventricle by two-dimensional echocardiography. F Am Soc Echocardiogr 1989;2:358-67.

20 Elhendy A, Cornel JH, Roelandt JRTC, van Domburg RT, Fioretti PM. Akinesis becoming dyskinesis during dobutamine stress echocardiography: A predictor of poor functional recovery after surgical revascularization. Ches 1996;110:155-8.

21 Elhendy A, Cornel JH, Roelandt JRTC, van Domburg RT, Geleijnse ML, Nierop PR, et al. Relation between contractile response of akinetic segments during dobutamine stress echocardiography and ischemia assessed by simultaneous 201 thallium SPECT. Am ₹ Cardiol 1996;77: 955-9.

22 Bellotti P, Fioretti PM, Forster T, McNeill AJ, El-Said EM, Salustri A, et al. Reproducibility of the dobutamineatropine echocardiography stress test. Echocardiography 1993;10:93-7.

23 Bolli R. Myocardial stunning in man. Circulation 1992; 86:1671-91.

24 Fragasso G, Chierchia SL, Lucignani G, Landoni C Conversano A, Gilardi MC, et al. Time dependence of residual tissue viability after myocardial infarction assessed by ${ }^{18} \mathrm{~F}$ fluorodeoxy glucose and positron emission tomography. Am f Cardiol 1993;72:G131-9.

25 Elhendy A, Geleijnse ML, Roelandt JRTC, Domburg RT, Cornel JH, TenCate FJ, et al. Evaluation by quantitative 99m-technetium MIBI SPECT and echocardiography of myocardial perfusion and wall motion abnormalities in patients with dobutamine-induced ST-segment elevation. Am ₹ Cardiol 1995;76:441-8.

26 Arora R, Ioachim L, Matza D, Horowitz SF. The role of ischemia and ventricular asynergy in the genesis of exercise-induced ST elevation. Clin Cardiol 1988;11: 127-39.

27 Gewirtz H, Sullivan M, O Reilly G, Winter S, Most A. Role of myocardial ischemia in the genesis of exercise-induced ST-segment elevation in previous anterior myocardial infarction. Am $\mathcal{F}$ Cardiol 1983;51:1293-305.

28 Haines DE, Beller GA, Watson DD, Kaiser DL, Sayre SL Gibson RS. Exercise-induced ST segment elevation 2 weeks after uncomplicated myocardial infarction: contributing factors and prognostic significance. $\mathcal{F} \mathrm{Am} \mathrm{Coll}$ Cardiol 1987;9:996-1003.

29 Shimonagata $T$, Nishimura $T$, Uehara $T$, Hayashida $K$, Saito M, Sumiyoshi T. Exercise-induced ST-segment elevation in leads over infarcted area and residual myocardial ischemia in patients with previous myocardial infarction. Am f Physiol Imaging 1990;5:99-106.

30 Margonato A, Ballarotto C, Bonetti F, Cappelletti A, Sciammarella M, Cianflone D, et al. Assessment of residual tissue viability by exercise testing in recent myocardial infarction: comparison of the electrocardiogram and infarction: comparison of the electrocardiogram and myocardial perfusio

31 Lanzarini L, Fetiveau R, Poli A, Cavalotti C, Griffini M, Previtali M. Significance of ST-segment elevation during dobutamine stress echocardiography in patients with acute myocardial infarction treated with thrombolysis. Eur Heart $\mathcal{~} 1$ 1996;17:1008-14.

32 Panza JA, Curiel RV, Laurienzo JM, Quyyumi AA Dilsizian V. Relation between ischemic threshold measured during dobutamine stress echocardiography and known indices of poor prognosis in patients with coronary artery disease. Circulation 1995;92:2095-101.

33 Elhendy A, Fioretti PM. Stress-induced ST-segment elevation after a recent myocardial infarction: myocardial necrosis, viability or both? Eur Heart f 1996;17:975-7.

34 Nishimura RA, Reeder GS, Miller FA Jr, Ildtrup DM Shub C, Seward JB, et al. Prognostic value of predischarge 2-dimensional echocardiogram after acute myocardial infarction. Am $f$ Cardiol 1984;53:429-32.

35 Braunwald E, Kloner RA. The stunned myocardium: prolonged, postischemic ventricular dysfunction. Circulation 1982;66:1146-9.

36 Galli M, Marcassa C, Bolli R, Giannuzzi P, Temporelli PL Imparato $\mathrm{A}$, et al. Spontaneous delayed recovery of perfusion and contraction after the first 5 weeks after anterior infarction. Evidence for the presence of hibernating myocardium in the infarcted area. Circulation 1994, 90:1386-97.

37 Daoud EG, Pitt A, Armstrong WF. Electrocardiographic response during dobutamine stress echocardiography Am Heart $\mathcal{f} 1995 ; 129: 672-7$. 